\title{
ĐỀ XUẤT QUI ĐỊNH KỸ THUẬT CÔNG TÁC BAY CHỤP ẢNH KHI SỬ DỤNG HẸ THỐNG TRẠM ĐỊNH VỊ VỆ TINH QUỐC GIA (CORS)
}

\author{
ĐÀO NGỌC LONG ${ }^{(1)}$, VỨNG TRỌNG KHA ${ }^{(2)}$ \\ (1)Viện Khoa học Đo đạc và Bản đồ \\ ${ }^{(2)}$ Truoòng Đại học Mỏ - Địa chất Hà Nội
}

\section{Tóm tắt:}

Hiện nay, hệ thống trạm Cors tại Việt nam đã được xây dụng, việc nghiên cưu sủ dụng các trạm này ưng dụng trong công tác bay chụp ảnh hàng không rất có ý nghĩa trong việc nâng cao hiệu quả công tác bay chụp, tính hiệu quả của việc đầu tur. Bài báo này trình bày qui định kỹ thuật công tác bay chụp ảnh khi sử dụng hệ thống trạm Cors để xác định các nguyên tố định hướng ngoài của ảnh phục vu công tác thành lập bản đồ và xây dụng cơ sở dũ liệu địa lý.

\section{Mở đầu}

Một trong những mục tiêu nghiên cứu của đề tài: "Nghiên cứu ứng dụng hệ thống mạng lưới trạm định vị vệ tinh cố định phục vụ xác định trực tiếp nguyên tố định hướng ngoài của ảnh". Mã số: TNMT.2017.07.03 là đưa ra được “Qui định kỹ thuật công tác bay chụp ảnh khi sử dụng hệ thống trạm CORS" (dự thảo). Nhóm thực hiện đề tài đã tiến hành các nghiên cứu về bản chất phương pháp Smart Base xử lý dữ liệu của nhiều trạm Base, thiết đặt và đo nối 06 điểm giả định tại các vị trí tương tự vị trí của các trạm CORS của Cục Đo đạc, Bản đồ và Thông tin địa lý Việt Nam xây dựng, với 02 khu vực bay chụp ảnh tại Lương Sơn - Hòa Lạc và Lục Nam - Sơn Động. Kết quả tính toán và đo đạc kiểm tra đảm bảo yêu cầu kỹ thuật đề ra, đáp ứng các tiêu chuẩn đánh giá trong quy định hiện hành. Qua đó, nhóm nghiên cứu đã đề xuất qui trình bay chụp ảnh theo phương pháp Smart Base và nguyên tắc sử dụng trạm CORS trong bay chụp ảnh như sau: (Xem hình 1, bảng 1)

2. Qui định kỹ thuật công tác bay chụp khi sử dụng hệ thống trạm CORS

Công tác bay chụp ảnh khi sử dụng hệ thống trạm CORS để tính toán xác định trực tiếp nguyên tố định hướng ngoài $\mathrm{EO}$ của từng tấm ảnh chụp có thể khái quát bằng quy trình thực hiện qua các bước chính như sau:

Bước 1. Công tác chuẩn bị.

Bước 2. Bay chụp ảnh.

Bước 3. Xử lý dữ liệu.

Bước 4. Kiểm tra, đánh giá, nghiệm thu chất lượng sản phẩm.

Bước 5. Giao nộp dữ liệu, sản phẩm.

Giải thích các bước trong qui định:

\subsection{Công tác chuẩn bị}

\subsubsection{Lập thiết kế bay:}

a) Thiết kế các đường bay: Lựa chọn thiết kế độ phân giải của ảnh chụp sao cho đáp ứng các yêu cầu kỹ thuật theo các quy định, từ đó căn cứ vào các thông số cơ bản như tiêu cự máy ảnh, độ cao trung bình của khu chụp để tính toán chọn độ cao bay chụp từ đó tính toán ra các thông số cơ bản về vùng phủ dọc và ngang tuyến bay dưới mặt đất để thiết kế các đường theo nguyên tắc cơ bản là các đường bay song song nhau sao cho ảnh chụp phủ kín khu đo đảm bảo phủ trùm ra ngoài khu vực đo vẽ theo quy định, đảm bảo giãn cách các tuyến theo các quy định bay chụp ảnh hiện hành, hướng bay được chọn sao cho đảm bảo an toàn cũng như tiết kiệm kinh phí, thường chọn hướng bay theo chiều dài khu đo. Có thể sử 
Bảng 1: Nguyên tắc sủ dụng trạm CORS trong bay chụp ảnh

\begin{tabular}{|c|c|}
\hline Số lượng trạm chọn & $\begin{array}{l}\text { Tối thiểu } 4 \text {, tối ưu } 10 \text {, tối đa tùy theo khả năng của chương } \\
\text { trình sử dưng tính. Nên có } 1 \text { trạm gần sân bay cất hạ cánh. }\end{array}$ \\
\hline Khoảng $c$ & 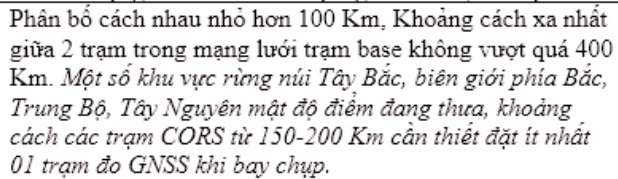 \\
\hline $\begin{array}{l}\text { Lựa cho } \\
\text { trong pl }\end{array}$ & 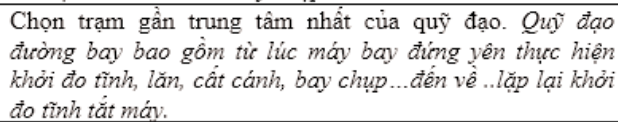 \\
\hline $\begin{array}{l}\text { Chiều dài } \\
\text { chính xác }\end{array}$ & $\begin{array}{l}\text { Khoảng cách tối đa từ máy bay tới trạm gần nhất không } \\
\text { quá } 70 \mathrm{Km} \text {. }\end{array}$ \\
\hline $\begin{array}{l}\text { Hình dạng của mạng lưới } \\
\text { smartbase }\end{array}$ & $\begin{array}{l}\text { Toàn quỹ đạo bay phài nằn } \\
\text { khép kín nối các điềm của }\end{array}$ \\
\hline $\begin{array}{l}\text { Tọa độ, độ cao của CORS và } \\
\text { thời gian đo dữ liệu CORS kể cà } \\
\text { các điểm thiết đặt thêm do tại } \\
\text { các khu vực chưa đủ mật độ } \\
\text { điểm. }\end{array}$ & $\begin{array}{l}\text { Tọa độ, độ cao các điểm base có độ chính xác RMS }< \pm 5 \\
\mathrm{~cm} \text { (điều này chắc chắn dư thừa đáp ứng với số liệu bình } \\
\text { sai của mạng lưới) } \\
\text { Giãn cách các trị đo tối thiểu là } 1 \mathrm{~s} \\
\text { Dữ liệu đo phải phủ í nhất trước } 2 \text { giờ và sau tối thiểu } 5 \\
\text { phút đối với thời gian thu dữ liệu GNSS gắn trên máy bay. }\end{array}$ \\
\hline $\begin{array}{l}\text { Lịch vệ tinh chính xác (chỉ cần } \\
\text { tới lịch Rapid là đủ độ chinh } \\
\text { xác) }\end{array}$ & $\begin{array}{l}\text { Lịch phài được sư dụng để tính toán tạo dữ liệu trạm tham } \\
\text { chiếu ảo theo phương pháp tính Smartbase. Lịch này phài } \\
\text { phủ trước và sau thời gian bay it nhất } 6 \text { tiếng. Lịch được } \\
\text { download từ trang mạng của các tổ chức quốc tế như IGS: } \\
\mathrm{ftp} / / \text { igs.ensg.ign.fr/pub/igs/products/ }\end{array}$ \\
\hline
\end{tabular}

dụng các phần mềm chuyên dụng kèm theo của các hệ thống dẫn đường chụp ảnh trên máy bay như Pos Track của hãng Applanix trên hệ thống POSAV. Ngoài ra, cần lựa chọn chủng loại máy bay phù hợp cho nhiệm vụ bay chụp đảm bảo các điều kiện lắp đặt, vận hành đáp ứng các yêu cầu bay chụp.

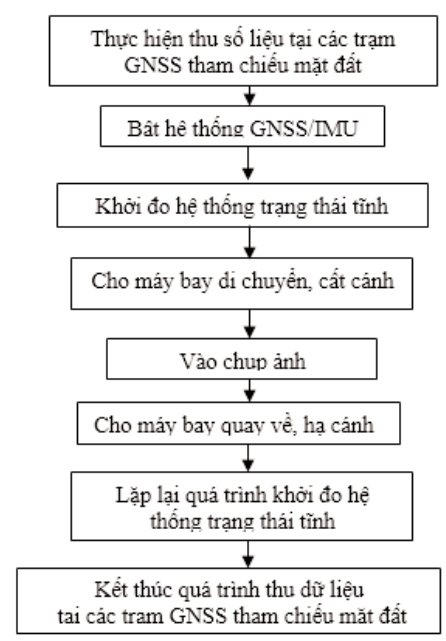

Hìn 1: Qui trình bay chup ảnh theo phwong pháp SmartBase

b) Lựa chọn các trạm Cors sẽ sử dụng làm các trạm tham chiếu (theo các nguyên tắc đã nêu trong bảng 1 . Đồng thời làm các công tác phối hợp như công văn đề nghị cấp dữ liệu theo yêu cầu kỹ thuật như tốc độ thu nhận dữ liệu (tối thiểu 1 giây), khoảng thời gian tiến hành bay chụp, danh sách các trạm để các cơ quan điều hành trạm được biết và có cơ sở thực hiện. Trong trường hợp cần thiết đặt thêm trạm base tại các khu vực rừng núi mật độ các trạm Cors còn thưa cần lựa chọn vị trí để thiết đặt các trạm bổ sung đảm bảo điều kiện thông thoáng, chống nhiễu tín hiệu, hậu cần thuận lợi cho trực thu dữ liệu dài ngày.

c) Thiết kế các điểm khống chế ảnh ngoại nghiệp:

Mặc dù công nghệ bay chụp có xác định trực tiếp EO đã giảm đáng kể các điểm khống chế phục vụ công tác tăng dày khống chế ảnh nhưng vẫn cần một số tối thiểu các điểm khống chế phục vụ các công tác kiểm tra, cũng như phát hiện các sai số hệ thống. Tối thiểu bố trí 05 điểm khống chế tại góc các khối và trung tâm khu bay. Ngoài ra tùy thuộc vào hình dạng của khối cần bố trí bổ sung các điểm khống chế thích hợp tại 
các vị trí trọng yếu như các góc khuyết, góc ngoặt khối, tại các khu vực hồ, sông lớn mà tại đó các điểm liên kết ảnh có khả năng sẽ ít và khối ảnh sẽ liên kết yếu. Các nguyên tắc chọn trích điểm vẫn tuân thủ các quy định hiện hành. Tại các khu vực không đảm bảo chọn trích cần thiết kế và xây dựng dấu mốc theo quy định.

\subsubsection{Kiểm định, kiểm tra, lắp đặt hệ thống thiết bị:}

a) Hệ thống thiết bị phải được bay kiểm định các thông số theo quy định của nhà sản xuất: chu kỳ thời gian, quy mô khu vực bay kiểm định, đồ hình bay, độ cao bay số lượng mốc, quy cách mốc, độ chính xác mặt phẳng, độ cao của các điểm mốc phục vụ cho bay kiểm định; Sử dụng phần mềm chuyên dụng để tính toán các thông số kiểm định theo yêu cầu như các véc tơ độ lệch giữa các hệ trục của hệ thống IMU, GNSS, máy ảnh.

b) Công tác bay kiểm tra định kỳ theo mùa vụ, tối thiểu phải thực hiện 1 lần/năm;

c) Kiểm tra hệ thống thiết bị dưới mặt đất trước khi lắp đặt lên máy bay;

d) Lắp đặt và kiểm tra vận hành thử hệ thống thiết bị trước khi tiến hành bay chụp, đảm bảo hệ thống máy ảnh, hệ thống định vị, dẫn đường tích hợp GNSS/IMU hoạt động đúng và đầy đủ các tính năng, hình ảnh chụp không bị các bộ phận của máy bay che chắn. Đồng thời sử dụng các thiết bị như toàn đạc điện tử xác định độ lệch (yêu cầu chính xác đến $\mathrm{cm}$ ) giữa tâm ăng ten thu nhận tín hiệu GNSS trên máy bay và điểm chuẩn được đánh dấu trên hệ thống máy ảnh.

2.1.3. Chuẩn bị đầy đủ về các nguồn lực sẽ được huy động cho thực hiện nhiệm vụ, dự án.

2.1.4. Thực hiện các công tác hiệp đồng với co quan điều hành trạm Cors. Đồng thời bố trí nhân lực, đo trực tại các trạm thiết đặt thêm (nếu có).

2.1.5. Thực hiện công tác xin phép bay, tiến hành tham gia phối hợp các công tác hiệp đồng bay (nếu được yêu cầu trong phép bay)

\subsection{Bay chup ảnh}

1. Thực hiện các công tác chuẩn bị trước khi bay như công tác vệ sinh, thông điện, kiểm tra thiết đặt các thông số kỹ thuật của máy ảnh, máy thu GNSS 2 tần (tốc độ thu tối thiểu 1 giây, đồng bộ với các trạm tham chiếu mặt đất), chụp kiểm tra thử, ghi chép nhật ký...

2. Tuân thủ các quy định bay như trong qui trình hình 1 .

3. Trong quá trình bay chụp ảnh luôn theo dõi hoạt động của các thiết bị định vị, dẫn đường, diễn biến của quá trình bay chụp, ghi chép đánh dấu những vị trí có độ lệch dẫn tuyến vượt quá yêu cầu, những vị trí mây, mù ảnh hưởng đến chất lượng ảnh... để chỉ huy bay quyết định có bay bổ sung ngay trên không hay không.

4. Khi kết thúc các chuyến bay trong ngày trút, sao lưu dữ liệu ảnh thô, dữ liệu GNSS/IMU. Đồng thời tiến hành kiểm tra, đánh giá chất lượng ảnh, chất lượng tín hiệu GNSS/IMU bằng các phần mềm chuyên dụng. Đồng thời ghi chép nhật ký, quyết định có bay bù bổ sung nếu cần thiết trong trường hợp kết quả kiểm tra dữ liệu nêu trên có phát hiện vấn đề. Công việc này rất cần thiết đòi hỏi thực hiện ngay để có thể tranh thủ moi điều kiện thời tiết tốt cho các ngày bay tiếp theo.

\subsection{Xỉ lý dũ liệu}

Việc tiến hành xử lý dữ liệu bay chụp được chia thành 2 khối xử lý độc lập: Xử lý ảnh và xử lý tính toán nguyên tố định hướng ngoài của ảnh.

Xử lý ảnh: Sử dụng phần mềm chuyên dụng để từ các dữ liệu ảnh thô tạo ra các tấm ảnh kết quả đã được tổ hợp màu, tăng cường chất lượng theo các định dạng chuẩn phục vụ các công tác tăng dày khống chế ảnh, đo vẽ, nắn ảnh.

Xử lý dữ liệu GNSS/IMU tính toán nguyên tố định hướng ngoài $\mathrm{EO}$ của ảnh

Công tác này tuân thủ theo quy trình tính toán cùng các tiêu chuẩn đòi hỏi về yêu cầu sản phẩm như: cơ sở toán học của EO, độ chính xác của các nguyên tố thành phần $\mathrm{X}, \mathrm{Y}, \mathrm{H}, \mathrm{Omega}$, Phi, 
Kapa của ảnh.

\subsection{Tổng hợp báo cáo}

Báo cáo được tổng hợp theo hai hình thức gồm bản cứng, bản mềm thể hiện đầy đủ các nội dung theo các quy định mô tả được đầy đủ quá trình tiến hành bay chụp, xử lý dữ liệu, chất lượng sản phẩm, cũng như sản phẩm giao nộp.

\subsection{Kiểm tra, nghiệm thu sản phẩm}

Quá trình đánh giá chất lượng sản phẩm cũng chia thành 2 sản phẩm, sản phẩm ảnh và sản phẩm EO, được đánh giá theo phân cấp.

a) Sản phẩm ảnh: Cần tuân thủ đảm bảo các tiêu chí theo các quy định hiện hành như độ phân giải ảnh, độ phủ ảnh, chất lượng hình ảnh, độ phủ trùm phạm vi chụp ảnh..

b) Sản phẩm EO: Được đánh giá dựa trên các tiêu chuẩn kỹ thuật hiện hành như tính đầy đủ mỗi một tấm ảnh chụp tương ứng phải có các giá trị EO cùng độ chính xác của chúng.

c) Tổng hợp báo cáo:

Báo cáo được tổng hợp theo hai hình thức gồm bản cứng, bản mềm thể hiện đầy đủ các nội dung theo các quy định mô tả được đầy đủ quá trình tiến hành bay chụp, xử lý dữ liệu, chất lượng sản phẩm, cũng như quy cách đóng gói, các khuôn dạng, định dạng của các sản phẩm giao nộp.

\subsection{Giao nộp dĩ liệu sản phẩm}

Là quá trình kiểm tra tính đầy đủ, toàn vẹn theo các danh mục sản phẩm đã được nêu trong báo cáo tổng hợp. Cơ quan nghiệm thu và đơn vị thực hiện sản xuất tiến hành đối chiếu rà soát trong khi nhập vào hệ thống lưu trữ tùy theo hình thức và phương thức thực hiện giao nhận. $\bigcirc$

\section{Tài liệu tham khảo}

[1]. Thông tư 39/2014/TT-BTNMT ngày 03 tháng 7 năm 2014 của Bộ trưởng Bộ Tài nguyên và Môi trường về "Qui định kỹ thuật thành lập mô hình số độ cao bằng công nghệ bay quét Lidar.

[2]. POSPac MMS GNSS-Inertial User Guide, Applanix Corporation, 2009. $\bigcirc$

\section{Summary}

Proposal on technical requirements for aerial photography in using Continuous Reference Stations (Cors)

Dao Ngoc Long

Vietnam Intitude of Geodesy and Cartography

Vuong Trong Kha

\section{Hanoi University of Mining and Geology}

Currently, the Cors in Vietnam have been built, which means that conducting research into the use of the system for aerial photography is important to improve the efficiency of flight photography and investment. This paper presents aerial photography specifications when using Cors in order to identify external elements of images for mapping and constructing geographic database. $\bigcirc$ 